\title{
Определение поглотительных характеристик водных растворов, содержащих эндофуллеренолы, по отношению к органическим соединениям
}

\author{
Спиридонова Е.А., Самонин В.В., Подвязников М.Л. \\ Санкт-Петербургский государственный технологический институт (технический университет), \\ Санкт-Петербург
}

Поступила в редакцию 26.12.2018 г.

DOI: https://doi.org/10.17308/sorpchrom.2019.19/652

Получены водные растворы эндофуллеренолов (общая формула $\left.\mathrm{Fe}_{0} \mathrm{C}_{60}(\mathrm{OH})_{26}\right)$ ), с концентрациями 0.1 и 0.4 мг/дм³ ${ }^{3}$. Исследована абсорбционная способность водных растворов эндофуллеренолов по отношению к органическим растворителям. В качестве органических растворителей использован бензол и о-ксилол. Анализ содержания эндофуллеренолов и органических растворителей в воде в работе проводился спектрофотометрическим методом. Сорбционные характеристики воды при введении в нее эндофуллеренолов в количестве 0.1 и 0.4 мг/дм ${ }^{3}$, повышаются по отношению к бензолу и о-ксилолу в ряде случаев более чем в 1.5 раза.

Ключевые слова: фуллерен, эндофуллеренол, оптическая плотность, спектрофотометрический анализ, вода, бензол, о-ксилол, раствор, абсорбент.

\section{Determination of absorption characteristics of aqueous solutions containing endofullerenoles, in relation to organic compounds}

\author{
Spiridonova E.A., Samonin V.V., Podvyaznikov M.L. \\ St. Petersburg State Technological Institute (Technical University), St. Petersburg
}

\begin{abstract}
Along with solid sorbent materials, in some cases there is a significant need for effective liquid absorbers. Such materials are needed to solve the environmental problems associated with excess of maximum permissible concentrations of toxic compounds in natural waters used on different industry, medicine and so on. This problem became the impetus for the search for new liquid absorbers, the absorption properties of which can vary widely, the introduction in their composition various modifiers. One of these modifiers is a new allotropic form of carbon - fullerene. Along with fullerenes, endohedral metallofullerenes - fullerene compounds containing one or more metal atoms inside their carbon framework, as well as fullerenols (fullerols) - hydrophilic water-soluble fullerene derivatives containing up to 26 groups of $\mathrm{OH}$, as well as oxygen bridges-are currently obtained.

One of the promising areas of application of fullerenes and their derivatives is the modification of materials, including sorption-active ones, by introducing micro-quantities of fullerenes into their composition in order to increase sorption activity. The authors of this paper suggested that the water introduced fullerene is able to change its properties with increasing absorption capacity. In the presented work studied the possibility of using to enhance the absorption properties of water in relation to organic compounds, endofullerenes is a water - soluble modifications of fullerene introduced endohedrally in the field of fullerene atom of iron. Investigated absorption capacity of aqueous solutions endofullerenes $\mathrm{Fe}_{0} @ \mathrm{C}_{60}(\mathrm{OH})_{26}$ with concentrations of 0.1 and $0.4 \mathrm{mg} / \mathrm{dm}^{3}$ in relation to organic solvents. Benzene and o-xylene were used as organic solvents. Content analysis endofullerenes and organic solvents in water was carried out spectrophotometrically. Sorp-
\end{abstract}


tion characteristics of water in the introduction to her endofullerenes in the amount of 0.1 and $0.4 \mathrm{mg} / \mathrm{dm}^{3}$, increased relative to the benzene and o-xylene, in some cases, more than 1.5 times.

Keywords: fullerene, endofullerenols, optical density, infrared spectrophotometry, water, benzene, o-xylene, solution, absorbent.

\section{Введение}

Сорбционные технологии занимают особое место в химической промышленности для обеспечения заданного качества продукции. Важную роль имеет получение новых эффективных сорбентов также для решения экологических проблем, связанных с превышением предельно допустимой концентрации токсичных соединений в природных водах, используемых на разных предприятиях, в медицине и пр. Данная проблема стала толчком к поиску новых материалов, обладающих повышенными сорбционными свойствами. Наряду с твердыми адсорбентами широко применяются жидкие поглотители, абсорбционные свойства которых зависят от состава и строения жидкости и могут широко варьироваться введением в их состав различных модификаторов.

Относительно недавно открытая, но уже широко известная, новая аллотропная форма углерода - фуллерен, характеризуется специфическим электронным строением, вследствие чего вызывает большой интерес в материаловедении, в том числе при получении новых сорбирующих материалов. Фуллерены [1] представляют собой объемные углеродные структуры с замкнутой поверхностью с четным количеством атомов углерода $\left(\mathrm{C}_{\mathrm{n}}\right.$, где $\left.\mathrm{n}>60\right) \mathrm{c} \mathrm{sp}^{2}$ гибридизацией, причем каждый атом углерода связан с тремя соседними атомами, а также $\pi$-связью между каждым атомом углерода и одним из его соседей. Фуллерены $\mathrm{C}_{60}$ и $\mathrm{C}_{70}$, так же, как и молекулы высших фуллеренов $\left(\mathrm{C}_{76}, \mathrm{C}_{78}, \mathrm{C}_{80}\right.$ и пр.) конденсируются в кристаллы, которые принято называть фуллеритами.

Наряду с фуллеренами в настоящее время получены эндоэдральные металлофуллерены - соединения фуллерена, содержащие внутри своего углеродного каркаса один или более атомов металлов, а также фуллеренолы (фуллеролы) - гидрофильные производные фуллерена, содержащие в своем составе до 26 групп ОН, а также кислородные мостики.

Строение эндометаллофуллерена (ЭМФ) определяется не только характеристиками структуры фуллереновой клетки, но и расположением атомов металлов внутри фуллерена. Слабосвязанные электроны на внешней оболочке ЭМФ придают молекулам свойства сильного восстановителя, что обусловливает их активность в химических реакциях присоединения. Важной особенностью фуллеренолов является их растворимость в воде [2].

Адсорбционную способность фуллеренов и их производных можно связать с поверхностными дефектами. Адсорбция на фуллеренах происходит в результате проникновения адсорбата в решетку. В частности, в кристалле фуллерена $\mathrm{C}_{60}$ роль микропор выполняет пространство между углеродными нанокластерами, в которое молекулы адсорбата проникают через дефекты. Диаметр внутренней полости приблизительно равен 0.5 нм. Толщина сферической оболочки фуллерена составляет около 0.1 нм, а внешний диаметр - около 0.7 нм [3].

Применение фуллеренов и их производных в биологии и медицине является одним из ведущих направлений. Из-за своей высокой электроотрицательности, молекулы фуллеренов способны выступать в химических реакциях как сильные окислители. Также одной из способностей фуллерена является возможность нейтрализовать свободные радикалы, путем захватывания у них свободных электронов на незанятые орбитали своего внешнего электронного облака. Такой механизм приводит к

Спиридонова и др. / Сорбционные и хроматографические процессы. 2019. Т. 19. № 1 
тому, что свободные радикалы теряют свои неспаренные электроны и превращаются в неактивные незаряженные неопасные молекулы [4].

Одним из важнейших направлений применения фуллеренов и их производных является модифицирование материалов, в том числе, сорбционно-активных, путем введения в их состав микроколичеств фуллеренов. В результате проведенных работ в этом направлении [5] было выявлено, что при введении микроколичеств фуллеренов увеличивается прочность и пластичность различных конструкционных, возрастает сорбционная емкость адсорбентов по отношению к металлам, органическим соединениям [6].

Исследованию сорбционных свойств адсорбентов, модифицированных фуллеренами, посвящен широкий круг работ. В частности, модифицированию подвергались активные угли [7], химические поглотители [8], силикагели [9], полимерные ионообменные смолы [10], неорганические ионооменные материалы [11]. Введение фуллеренов в данные твердые пористые материалы привело к значительному повышению их сорбционной емкости.

Наряду с использованием в качестве поглотительных материалов твердых адсорбентов, в процессах очистки успешно применяются жидкие абсорбенты [12]. При этом, как известно, поглотительные свойства жидкостей по отношению к газам и парам во многом зависят от растворенных в них соединений [13]. Как было показано авторами ранее [14] введение фуллеренов в водную среду повышает ее поглотительные характеристики по отношению к органическим соединениям. При этом высказано предположение, что вводимый в воду фуллерен способен изменять ее свойства с изменением абсорбционной емкости. В водной системе фуллерен образует вокруг себя гидратные оболочки, которые изменяют кластерное строение воды, тем самым, это приводит к изменению растворимости соединений в воде, в том числе и органических.

В настоящей работе исследуется возможность использования для повышения абсорбционных свойств воды по отношению к органическим соединениям, эндофуллеренолов - водорастворимой модификации фуллеренов с введенным эндоэдрально в сферу фуллерена атомом железа.

\section{Эксперимент}

Методы исследования. В качестве объектов исследования в данной работе были выбраны следующие материалы: Эндофуллеренол $\mathrm{C}_{@}\left(\right.$ состав - Fe @ $\left.\mathrm{C}_{60}(\mathrm{OH})_{26}\right)$, растворимость в воде $32 \mathrm{mг} / \mathrm{cm}^{3}$, производитель ПИЯФ, г. Гатчина. Содержание $\mathrm{C}_{60}$ составляет $60.5 \%$ (по массе).

Для определения содержания органических веществ в воде использовали спектрофотометрический метод [15], основанный на поглощении органическими веществами электромагнитных колебаний в ультрафиолетовой (УФ) области. Концентрацию исследуемого вещества в воде определяли при выбранной оптимальной длине волны [16]. Спектры поглощения определяемого вещества в растворе измеряли в сравнении со спектрами растворителя.

Приготовление водного раствора эндофуллеренола осуществлялось следующим образом. К навеске $\mathrm{Fe} @ \mathrm{C}_{60}(\mathrm{OH})_{26}\left(\mathrm{~m}=0.6\right.$ мг) добавлялось $200 \mathrm{~cm}^{3}$ воды, после чего раствор подвергался длительному перемешиванию на магнитной мешалке. Полученный раствор разбавлялся до 1 дм $^{3}$ до концентрации $\mathrm{C}_{60}=0.4 \mathrm{мг} /$ дм$^{3}$. Для проведения исследований были выбраны следующие концентрации (в пересчете на $\mathrm{C}_{60}$ ): $0.05 ; 0.1 ; 0.2$ и 0.4 мг/дм ${ }^{3}$, поэтому исходный раствор разбавлялся в 8,4 и 2 раза, соответственно.

Спиридонова и др. / Сорбционные и хроматографические процессы. 2019. Т. 19. № 1 
Введение бензола и о-ксилола в воду и водный раствор эндофуллеренола осуществлялось до расслоения раствора на две фазы, с дальнейшим отделением водного раствора органического соединения от органической фазы с определением оптической плотности раствора.

\section{Обсуждение результатов}

Исследование стабильности растворов эндофуллеренолов. Оценка стабильности водного раствора эндофуллеренола. На первом этапе была проведена оценка стабильности водного раствора эндофуллеренола во времени. Это делалось для нахождения устойчивой системы пришедшей в равновесное состояние, с возможностью ее дальнейшего использования в качестве абсорбента.

Рис. 1 отображает зависимость оптической плотности водного раствора от длительности экспозиции (отстаивания).

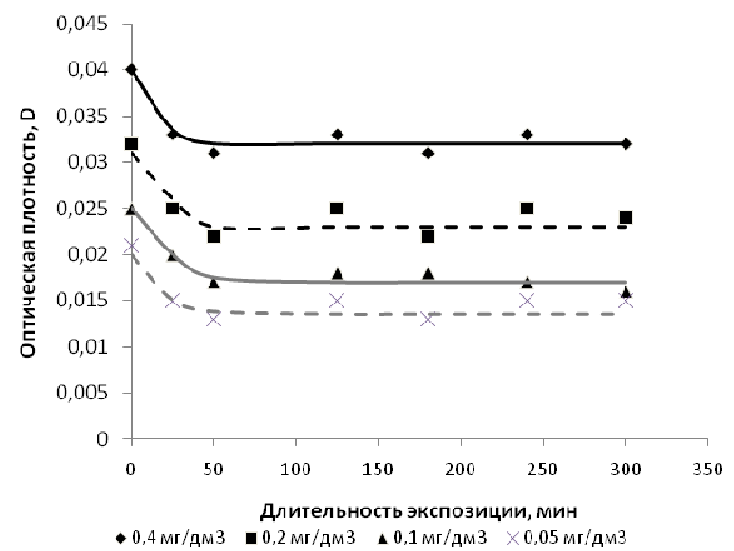

Рис. 1. Изменение оптической плотности раствора эндофуллеренола С@ от времени экспозиции $(\lambda=240$ нм $)$

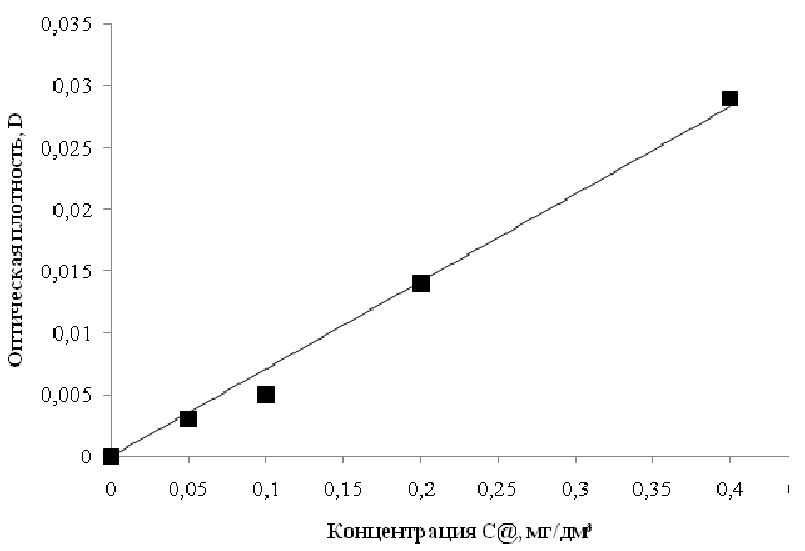

Рис. 2. Зависимость оптической плотности раствора от концентрации эндофуллеренола С@

При экспозиции растворов значения оптической плотности снижаются. Для эндофуллеренола за 30 мин наблюдается падение плотности с 0.040 до 0.032 (на $18 \%$ ) - для концентрации эндофуллеренола 0.4 мг/дм ${ }^{3}$ и с 0.021 до 0.013 (на $31 \%$ ) - для концентрации 0.05 мг/ дм ${ }^{3}$. Вероятно, в этом случае, система стремится к определенному равновесию.

При этом построение зависимости оптической плотности водных растворов от концентрации эндофуллеренола в воде (рис. 2), для растворов эндофуллеренолов с концентрациями $0.05 ; 0.1 ; 0.2$ и 0.4 мг/дм показало, что с увеличением концентрации эндофуллеренола в воде линейно увеличивается оптическая плотность раствора, с соблюдением в данном интервале концентраций закона Бугера-Ламберта-Бера.

Как видно из представленного графика, оптические плотности растворов эндофуллеренолов воде при всех данных концентрациях имеют крайне невысокие значения и незначительно превышают оптическую плотность воды. Это можно объяснить тем, что частицы фуллерена в крайне небольших количествах равномерно распределены в объеме раствора и не поглощают свет в значительной степени при данных длинах волн.

Выбор оптимальной длины волны для определения содержания органических соединений в воде. Для работы с растворами, в которые добавлены органические вещества, необходимо определить оптимальную рабочую длину волны. В пробы воды были добавлены небольшие, не превышающие их растворимость, количества бензола $\left(\mathrm{C}=0.44\right.$ мг/дм $\left.{ }^{3}\right)$ и о-ксилола $\left(\mathrm{C}=0.14\right.$ мг/дм $\left.{ }^{3}\right)$, и измерена оптическая плот- 
ность при различных длинах волн. Далее полученные значения были представлены в виде графика (рис. 3).

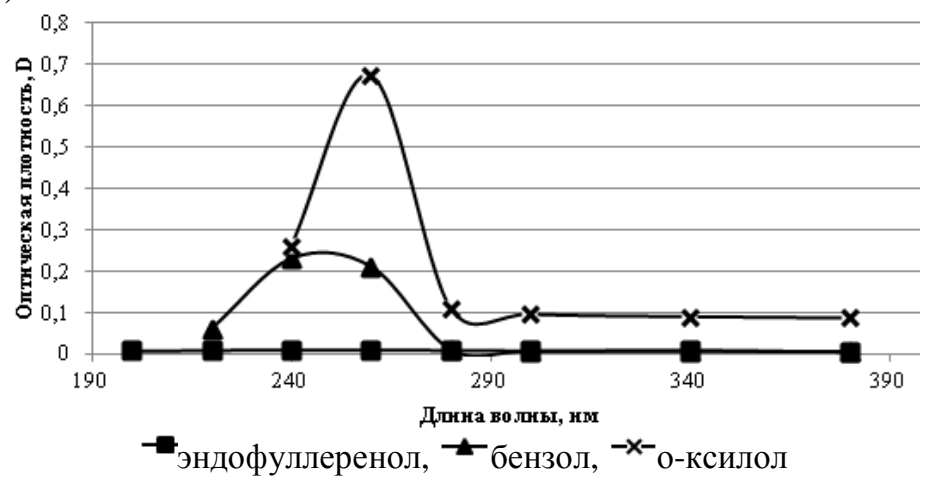

Рис. 3. Зависимость оптической плотности водных растворов органических соединений от длины волны

По данным графикам были найдены максимумы оптических плотностей для бензола и о-ксилола $\left(\lambda_{\text {опт }}(\right.$ бензол $)=240$ нм и $\lambda_{\text {опт }}($ о-ксилол $)=260$ нм $)$, соответствующие максимумам поглощения.

Для сравнения на графике приведены оптические плотности раствора эндофуллеренола $\left(\mathrm{C}=0.2 \mathrm{\text {мг/дм }}{ }^{3}\right)$ в диапазоне $\lambda=(200-380)$ нм. Как видно из данного графика, а также, из сравнения рис. 1 и 2 с рис. 3, оптическая плотность растворов эндофуллеренолов в воде очень мала (0.015-0.040) по сравнению с плотностью растворов бензола и о-ксилола в воде (соответственно, 0.24 и 0.68 ) и составляет для бензола в усредненном выражении $8 \%$, а для о-ксилола $3 \%$.

Определение поглотительной способности растворов эндофуллеренола. На следующем этапе работы были определены поглотительные характеристики водных растворов эндофуллеренола. Как видно из аналитического обзора, в водной среде вокруг молекулы эндофуллеренола образуются гидратные оболочки, что приводит к изменению структуры воды, изменяя ее способность поглощать различные вещества за счет повышения их растворимости.

Определение поглотительной способности по бензолу. Для индикации величины абсорбции бензола раствором эндофуллеренола, была выбрана длина волны $\lambda=230$ нм. Оптическая плотность получаемых растворов бензола, сравнивалась с оптической плотностью растворителей (воды и растворов эндофуллеренола). Рис. 4 отображает результаты измерения оптической плотности исследуемых растворов при добавлении бензола.

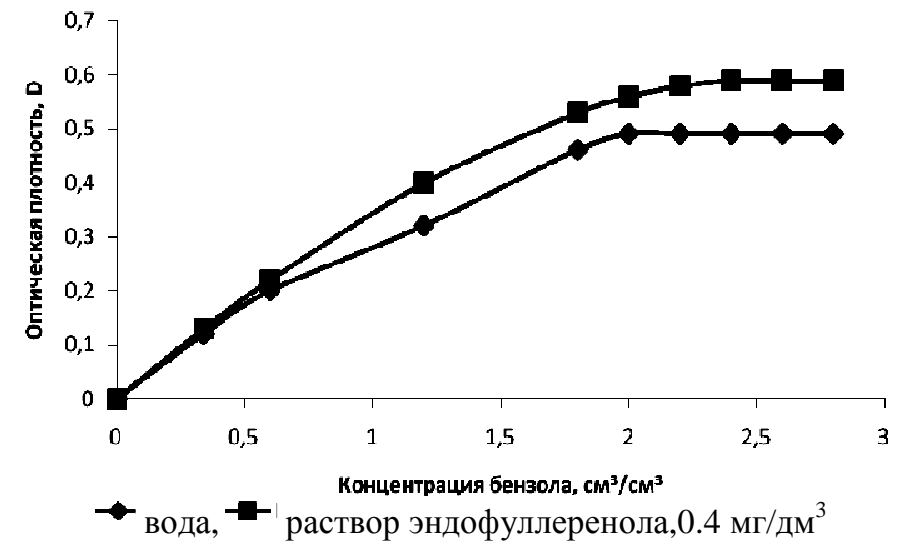

Рис. 4. Поглотительная способность воды и раствора эндофуллеренола по бензолу

Оценка выхода кривых на равновесную концентрацию бензола в водных системах показывает, что для воды эта концентрация составляет величину в диапазоне 
экспериментально полученных значений $1.8-2.0 \mathrm{~cm}^{3} / \mathrm{m}^{3}$, а для раствора эндофуллеренола в воде с концентрацией 0.4 мг/дм ${ }^{3}$, эта концентрация варьируется от 2.2 до $2.4 \mathrm{~cm}^{3} / \mathrm{m}^{3}$.

Был проведен расчет, основанный на равновесных значениях оптической плотности для растворов бензола в воде и в растворе эндофуллеренола. При этом было предположено, что в данной области низких концентраций соблюдается линейный характер зависимости оптической плотности от концентрации бензола, аналогично линейному характеру зависимости оптической плотности растворов эндофуллеренолов от их концентрации. Полученные результаты приведены в табл.1.

Таблица 1. Значения оптической плотности, равновесной концентрации исследуемых растворов и поглотительной емкости эндофуллеренола по бензолу

\begin{tabular}{|c|c|c|}
\hline Показатель & Вода & Раствор эндофуллеренола $\left(0.4 \mathrm{мг} /\right.$ дм$\left.^{3}\right)$ \\
\hline $\mathrm{D}$ & 0.49 & 0.59 \\
\hline Сбензол, $\mathrm{cm}^{3} / \mathrm{M}^{3}\left(\mathrm{мг} /\right.$ дм $\left.^{3}\right)$ & $1.9(1.7)$ & $2.3(2.0)$ \\
\hline $\mathrm{A}, \Gamma / \Gamma$ & - & 5.0 \\
\hline $\mathrm{A}^{*}, \Gamma / \Gamma$ & - & 0.75 \\
\hline
\end{tabular}

Основываясь на результатах, полученных в ходе эксперимента, можно говорить об увеличении оптической плотности растворов эндофуллеренолов по сравнению с водой при добавлении к ним бензола. Таким образом, введение эндофуллеренолов в воду способствует повышению ее поглотительной емкости по бензолу.

В связи с этим возникает вопрос, обусловлено ли повышение поглотительной способности воды при введении в нее эндофуллеренола изменением ее поглотительных характеристик или это связано с сорбционной способностью самого эндофуллеренола. Произведенный расчет показывает, что величина сорбции бензола, приведенная к единице массы эндофуллеренола в составе раствора, составляет $A=5$ г/г. Если учесть, что молекулярная масса использованного в работе эндофуллеренола составляет 1218 а.е.м, то соответствующая молекулярная масса поглощенного бензола составит 6090 а.е.м. или 78 молекул. Известно, что молекула $\mathrm{C}_{60}$, в которой все атомы эквивалентны, вследствие высокой симметрии, имеет сферическую форму с расстоянием от центра до ядер атомов около 0.36 нм и ван-дер-ваальсовым радиусом около 0.5 нм. [17]. Для расчетов примем, что радиус молекулы эндофуллеренола составляет 0.5 нм. Следовательно, площадь поверхности молекулы составит 3.13 нм$^{2}$. Критический диаметр молекулы бензола составляет по различным данным величину 0.56-0.60 нм. Приняв среднее значение получим значение посадочной площадки молекулы, которая составит 0.26 нм$^{2}$. Таким образом, при плотнейшей упаковке, на молекуле эндофуллеренола сможет уместиться не более 12 молекул бензола. С учетом того, что их количество по результатам эксперимента составляет 78 единиц, и, при-

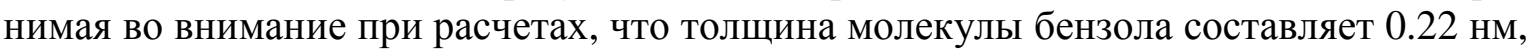
что ведет к повышению площади поверхности для сорбции молекул бензола, получаем, что количество слоев на поверхности эндофуллеренола составит величину практически равную 3. Так как в рассматриваемом случае имеет место насыщенный раствор бензола в водных средах, следует заключить, что сорбционная способность материала, характеризующаяся наличием 3-х монослоев на активной поверхности высокой кривизны, вполне может быть достигнута. При этом необходимо учесть, что вода, как видно из табл. 1, сама обладает определенной сорбционной способностью по отношению к бензолу. Принимая во внимание эту поправку, величину сорбции на эндофуллереноле следует скорректировать на равновесное содержание эндофуллеренола в воде, в результате чего величина сорбции составит значение $\mathrm{A}^{*}=$

Спиридонова и др. / Сорбционные и хроматографические процессы. 2019. Т. 19. № 1 
0.75 г/г и число сорбционных слоев бензола на эндофуллереноле не превысит одного.

Определение поглотительной способности по о-ксилолу. Длина волны, при которой проводилось определение абсорбции о-ксилола в системе, составила $\lambda=280$ нм. Оптическая плотность получаемых растворов о-ксилола также сравнивалась с оптической плотностью растворителей (воды и растворов эндофуллеренола). В соответствии со справочным материалом растворимость о-ксилола в воде достаточно мала (менее $0.015 \%$ (по массе) $=0.17 \mathrm{~cm}^{3} / \mathrm{m}^{3}$ ) [18].

На рис. 5 приведены результаты измерения оптической плотности исследуемых растворов с добавлением о-ксилола.

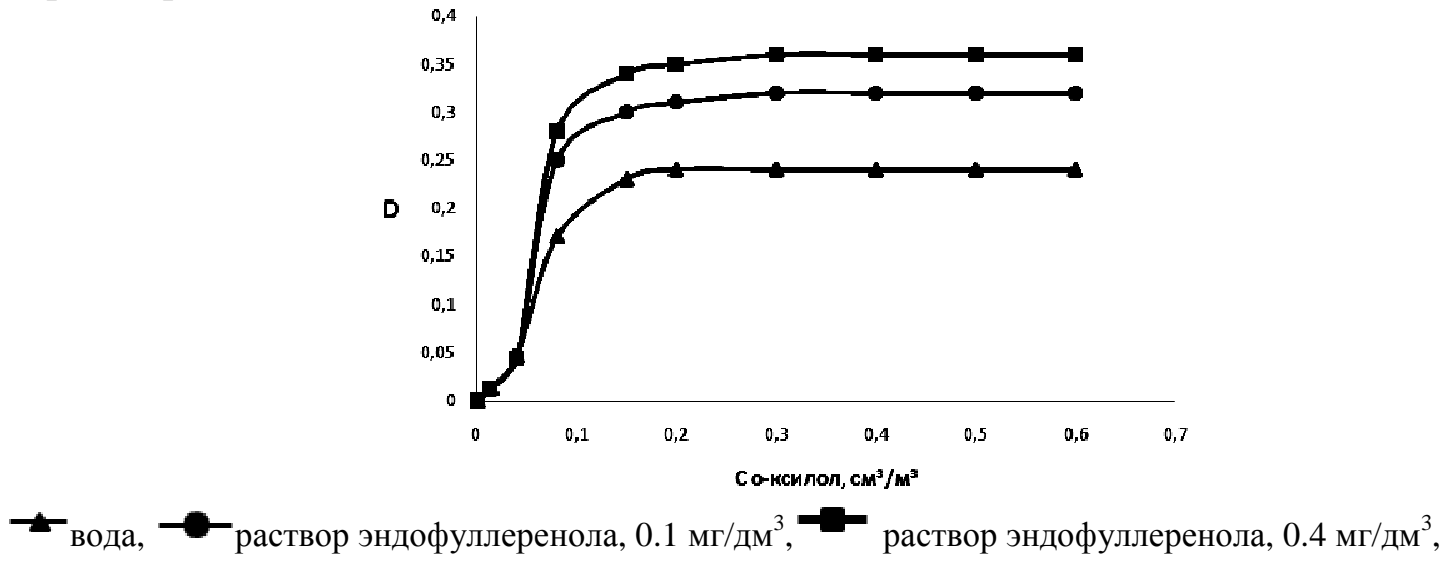

Рис. 5. Поглотительная способность воды и водных растворов эндофуллеренола по о-ксилолу

Оценка выхода кривых на равновесную концентрацию показывает, что для воды эта концентрация составляет около $0,20 \mathrm{~cm}^{3} / \mathrm{m}^{3}$ (по экспериментальным точкам от 0.15 до $0.20 \mathrm{~cm}^{3} / \mathrm{m}^{3}$ ). Для растворов эндофуллеренола в воде, как с концентрацией 0.1 мг/л, так и 0.4 мг/л, это содержание составляет величину в пределах $0.20-0.30$ $\mathrm{cm}^{3} / \mathrm{m}^{3}$.

Более точный расчет был также проведен с использованием значений величин оптической плотности, исходя из предположения о линейном характере зависимости оптической плотности от концентрации о-ксилола в водных системах. Полученные результаты приведены в табл. 2.

Таблица 2. Значения оптической плотности, равновесной концентрации исследуемых растворов и поглотительной емкости эндофуллеренола по о-ксилолу

\begin{tabular}{|c|c|c|c|}
\hline \multirow{2}{*}{ Показатель } & \multirow{2}{*}{ Вода } & \multicolumn{2}{|c|}{ Раствор эндофуллеренола, мг/дм ${ }^{3}$} \\
\cline { 3 - 4 } & & 0.1 & 0.4 \\
\hline $\mathrm{D}$ & 0.24 & 0.32 & 0.36 \\
\hline $\mathrm{C}_{\text {о-ксилол, } \mathrm{cm}^{3} / \mathrm{M}^{3}\left(\mathrm{м} \Gamma / \text { дм }^{3}\right)}$ & $0.17(0.15)$ & $0.23(0.20)$ & $0.26(0.23)$ \\
\hline $\mathrm{A}, \Gamma / \Gamma$ & - & 2.0 & 0.58 \\
\hline $\mathrm{A}^{*}, \Gamma / \Gamma$ & - & 0.5 & 0.2 \\
\hline
\end{tabular}

Конечная концентрация о-ксилола в исследуемых водных системах увеличилась относительно исходной концентрации о-ксилола в воде, для раствора эндофуллеренола с концентрацией 0.1 мг/дм ${ }^{3}$ в 1.3 раза, а для раствора эндофуллеренола с концентрацией 0.4 мг/дм ${ }^{3}$ в 1.5 раза.

Величина сорбционной емкости эндофуллеренола (А) с предположением, что весь о-ксилол сорбируется только на нем, составила значения, соответственно 2,0 и 0.58 г/г. С учетом сорбционной емкости воды по о-ксилолу $\left(0.15\right.$ мг/дм $\left.{ }^{3}\right)$, расчетная 
величина сорбционной емкости эндофуллеренола по отношению к о-ксилолу (А*) составила 0.5 и 0.2 г/Г для растворов эндофуллеренола с содержанием эндофуллеренола, соответственно, 0.1 и 0.4 мг/ дм³ .

Следует отметить, что если бы приращение поглотительной емкости растворов эндофуллеренолов по сравнению с водой по о-ксилолу было обусловлено только сорбционной способностью эндофуллеренолов, то повышение концентрации оксилола в растворе эндофуллеренола вело бы к повышению расчетной сорбционной емкости эндофуллеренолов. Однако мы наблюдаем обратную картину, что говорит о том, что повышение поглотительной способности водного раствора эндофуллеренола обусловлено не только высокой сорбционной способностью растворенного эндофуллеренола, но и увеличением поглотительных свойств непосредственно воды к органическим компонентам при повышении количества эндофуллеренола в раствоpe.

По всей вероятности, эндофуллеренол усиливает взаимодействие воды с такими неполярными молекулами как бензол и о-ксилол. Это можно объяснить изменением полярности поглощаемых веществ за счет индуцированного дипольного момента (полярная молекула начинает оказывать влияние на неполярную). Эндофуллеренол обладает сильными акцепторными свойствами из-за дефицита электронов [19], также он поляризуем. Постоянный диполь способен вызвать распределение зарядов в неполярной молекуле. Заряженные концы полярной молекулы воздействуют на электронные облака неполярной молекулы, что приводит к их смещению в сторону положительного заряда, тем самым, делая неполярную молекулу полярной, усиливая ее взаимодействие с водой и повышая растворимость.

С другой стороны, можно сделать предположение, что введение эндофуллеренолов в воду приводит к «структурированию воды». Молекулы воды, которые располагаются в исходной воде в виде небольших ассоциатов, образующихся за счет водородных связей, группируются и структурируются в более крупные агломераты вокруг молекулы эндофуллеренола, которая обладает электронно-дефицитным $\pi$ электронным кольцом. Идею об «ажурной» структуре воды, которая используется до сих пор [20], высказали в 1933 году Дж.Берналл и Р.Фаулер. Так как вода обладает весьма сильным электрическим моментом, который образован за счет того, что оба атома водорода примыкают к кислороду с одной и той же стороны, введение в воду такой молекулы как эндофуллеренол, способствует большей степени структурирования воды, которое наиболее выражено для льда. Предполагается, что вследствие этого можно представить структуру воды ажурной, с включением в межмолекулярные полости других молекул. И, если гидрофильные молекулы, растворенные в воде, замещают молекулы воды в узлах ее решетки, то гидрофобные молекулы фиксируются в полостях ажурной структуры воды за счет Ван-дер-Ваальсовых взаимодействий. Таким образом, повышаются поглотительные свойства (сродство) воды по отношению к органическим растворителям (бензол, о-ксилол), а также к молекулам эндофуллеренола. При этом взаимное притяжение неполярных органических молекул и их адсорбционное взаимодействие снижается вследствие его ослабления и блокирования гидратными оболочками при достаточно низких концентрациях органических соединений в воде.

\section{Заключение}

Получены водные растворы на основе эндофуллеренола различных концентраций.

Спиридонова и др. / Сорбционные и хроматографические процессы. 2019. Т. 19. № 1 
Исследовано влияние концентрации водных растворов эндофуллеренолов на их стабильность. Показано, что раствор эндофуллеренола приходит в состояние равновесия с неизменным значением оптической плотности в через 30-50 мин.

Определены поглотительные характеристики водных растворов эндофуллеренолов по бензолу и о-ксилолу. Показано, что абсорбционная способность по бензолу водных растворов эндофуллеренолов с концентрацией 0.4 мг/дм ${ }^{3}$ повышается на $20 \%$, а по о-ксилолу для водных растворов эндофуллеренолов с концентрациями 0.1 и 0.4 мг/дм ${ }^{3}$ соответственно, на 35 и $53 \%$. При этом равновесная сорбционная емкость эндофуллеренолов по бензолу и о-ксилолу составила, соответственно, 0.75 г/г и $0.2-0.5$ г/г.

Показано, что повышение поглотительной способности водного раствора эндофуллеренола обусловлено не только высокой сорбционной способностью растворенного эндофуллеренола, но и повышением поглотительных свойств воды при введении в нее эндофуллеренола.

Результаты получены в рамках государственного задания Минобрнауки России № 10.7499.2017/8.9 на выполнение государственных работ в сфере научной деятельности инициативные научные проекты «Научные основы создания гидрофобных микропористых углеродных адсорбентов для повышения селективности сорбиионного поглощения микропримесей органических соединений из водных и завлажненных газовых сред» (ЕГИСУ НИОКР № АААА-А17-117040510271-1)

\section{Список литературы}

1. Сидоров Л.Н. Юровская М.А. Борщевский А.Я. Фуллерены. М. Экзамен. 2004. 688 c.

2. Ширинкин С.В., Шапошников А.А., Волкова Т.О., Андриевский Г.В. и др. // Научные ведомости. 2012. № 9. С. 122-129.

3. Елецкий А.В., Смирнов Б.М. // УФН. 1995. Т. 165 (9). С. 977-1009.

4. Гончарова Е.А. Дисс. канд. техн. наук. 2017. $113 \mathrm{c}$.

5. Буря А.И., Ткачев А.Г., Мищенко С.В., Наконечная Н.И. // Пластические массы. 2007. № 12. С. 36-41.

6. Самонин В.В., Подвязников М.Л., Никонова В.Ю., Спиридонова Е.А. и др. Сорбирующие материалы, изделия, устройства и процессы управляемой адсорбции. СанктПетербург. Наука. 2009. 271 с.

7. Самонин В.В., Никонова В.Ю., Подвязников М.Л. // Химическая технология. 2015. T. 16. № 2. C. 74-79.

8. Самонин В.В., Никонова В.Ю., Подвязников М.Л., Абрамова М.А. // ЖПХ. 2012. Т. 85. № 2. C. 177-181.

9. Самонин В.В., Подвязников М.Л., Спиридонова Е.А. // Известия СанктПетербургского государственного технологического института (технического универcumema). 2011. № 11 (37). C. 58-60.
10. Самонин В.В., Подвязников М.Л., Спиридонова Е.А., Киселева В.Л и др. // Альтернативная энергетика и экология. 2012. № 10 (114). C. 50-54.

11.Морозова В.Ю., Подвязников М.Л., Самонин В.В. // ЖПХ. 2015. Т. 88. Вып. 10. С. 1427-1431.

12.Касаткин А.Г. Основные процессы и аппараты химической технологии. М. ООО ТИД «Альянс». 2004. 753 с.

13.Краснов К.С. Физическая химия, в 2 т. М. Высшая школа. 2001. 512 с.

14.Самонин В.В., Спиридонова Е.А., Тихомирова А.Д., Подвязников М.Л. // Альтернативная энергетика и экология. 2014. № 19 (159). C. 63-69.

15.Применение УФ-спектроскопии для количественного определения органических веществ. Режим доступа: https://studfiles.net/preview/2037973/page:5/, свободный. (дата обращения 10.12.2018).

16.Булатов М.И., Калинкин И.П. Практическое руководство по колориметрическим и спектрофотометрическим методам анализа. М. Химия. 1965. 222 с.

17.Гусев А.И. Наноматериалы, наноструктуры, нанотехнологии. М. Физматлит, 2007.416 c.

18.Коган В.Б., Фридман В.М., Кафаров В.В. Справочник по растворимости. Бинар- 
ные системы. Москва-Ленинград. АН СССР. 1961. T. 2. $961 \mathrm{c}$.

19.Сжогина А.А. Дисс. канд. физ.-мат. наук. 2017. 144 с.

\section{References}

1. Sidorov L.N., Yurovskaya M.A., Borschevsky A.Ya. Fullerenes. M., publishing House "Exam", 2004, 688 p.

2. Shirinkin S.V., Shaposhnikov A.A., Volkova T.O., Andrievsky G.V. et al., Scientific Bulletin, 2012, Vol. 9, pp. 122-129.

3. Eletskii A.V., Smirnov B.M., Phys., 1995, Vol. 165 (9), pp. 977-1009.

4. Goncharova E.A. Diss. cand techn. nauk, 2017, 113 p.

5. Burya A.I., Tkachyov A.G., Mishchenko S.V., Nakonechnaya N.I., Plastic masses, 2007, Vol. 12, pp. 36-41.

6. Samonin V.V., Podvyaznikov M.L., Nikonova V.Yu., Spiridonova E.A. et al., Sorbent materials, products, devices and processes of controlled adsorption. Saint Petersburg, Nauka, 2009, $271 \mathrm{p}$.

7. Samonin V. V., Nikonova V., Podvyaznikov M. L., Chemical technology, 2015, Vol. 16, No 2, pp. 74-79.

8. Samonin V.V., Nikonova V.Yu., Podvyaznikov M.L., Abramov M.A., Zhph, 2012, Vol. 85, No 2, pp. 177-181.

9. Samonin V.V., Podvyaznikov M.L., Spiridonova E.A., Proceedings of the St. Petersburg state technological Institute (technical University), 2011, No 11 (37), pp. 58-60.

10.Samonin V.V., Podvyaznikov M.L., Spiridonova E.A., Kiseleva V.L. et al., Alternative energy and ecology, 2012, No 10 (114), pp. 5054.

Спиридонова Елена Анатольевна - к.т.н., научный сотрудник кафедры химии и технологии материалов и изделий сорбционной техники СанктПетербургского государственного технологического института (технического университета), СанктПетербург

Самонин Вячеслав Викторович - д.т.н, професcop, заведующий кафедрой химии и технологии материалов и изделий сорбционной техники СанктПетербургского государственного технологического института (технического университета), СанктПетербург

Подвязников Михаил Львович - д.т.н, доцент, профессор кафедры химии и технологии материалов и изделий сорбционной техники СанктПетербургского государственного технологического института (технического университета), СанктПетербург
20.Когановский А.М., Левченко Т.М., Кириченко В.А. Адсорбция растворенных веществ. Киев. Наук. Думка. 1977. 223 с.

11.Morozova V.Yu., Podvyaznikov M.L., Samonin V.V., Zhph., 2015, No 10, pp. 14271431.

12. Kasatkin A.G. Basic processes and apparatus of chemical technology. M., LLC Ted "Alliance", 2004, $753 \mathrm{p}$.

13.Krasnov K.S. Physical chemistry, in $2 \mathrm{t}$. M., Higher school, 2001, 512 p.

14.Samonin V.V., Spiridonova E.A., Tikhomirov A.D., Podvyaznikov M.L., Alternative energy and ecology, 2014, No 19 (159), pp. 6369.

15.Application of UV spectroscopy for quantitative determination of organic substances. Available at: https://studfiles.net/preview/2037973/page:5/, free (accessed 10 December 2011).

16.Bulatov M.I., Kalinkin I.P. Practical guide to colorimetric and spectrophotometric methods of analysis, M., Izd. "Chemistry", 1965, 222 p.

17.Gusev A.I. Nanomaterials, nanostructures, nanotechnology. Moscow, Fizmatlit, 2007, 416 p.

18. Kogan V.B. Handbook of solubility. Binary systems. Moscow-Leningrad, the USSR Academy of Sciences, 1961, Vol. 2, 961 p.

19.Zhogina A.A. Diss. cand. phis-mat. nauk, 2017, 144 p.

20.Kogan A.M., Levchenko T.M., Kirichenko V.A. Adsorption of dissolved substances. Kiev, Sciences. Dumka, 1977, 223 p.

Spiridonova Elena A. - candidate of technical Sciences, Scientific employee of the Department of Chemistry and Technology of Materials and Products of Sorption Technology of the St. Petersburg State Technological Institute (Technical University), St. Petersburg, e-mail: spiridonova_elena@live.ru

Samonin Vyacheslav V. - doctor of technical Sciences, Professor, Head of the Department of Chemistry and Technology of Materials and Products of Sorption Technology of the St. Petersburg State Technological Institute (Technical University), St. Petersburg, email: samonin@1ti-gti.ru

Podvyaznikov Mikhail L. - doctor of technical Sciences, docent, Professor of the Department of Chemistry and Technology of Materials and Products of Sorption Technology of the St. Petersburg State Technological Institute (Technical University), St. Petersburg 